\title{
EXCISION OF THE TRAPEZIUM FOR OSTEOARTHRITIS OF THE TRAPEZIO-METACARPAL JOINT
}

\author{
IV. Harvey Girris, Tunbridge W'ells, England *
}

Osteoarthritis of the trapezio-metacarpal joint may be monarticular and probably is often traumatic in origin. Table $I$ is an analysis of fifteen patients with disability severe enough to justify operation. The series is small because the condition is not very common. It is found in later life and mainly in women. The right side is more often affected than the left but both joints are sometimes involved. The figure for bilateral cases rather underestimates the frequency; a few other patients had slight symptoms on the opposite side not severe enough to require operation. Although there was a history of injury in only a third of the patients, there may have been unremembered injuries in others, and it is probable that injury is one of the main factors in causation. More than half of the patients were under the age of sixty and therefore required painless use of the thumbs for active work.

With regard to treatment, palliative measures cannot restore the articular surfaces, while arthrodesis of the joint is not easy, requires prolonged after-treatment and limits movement of the thumb. Removal of the trapezium is a simple form of arthroplasty and the results of this operation will be discussed.

Clinical features-All the patients complained

TABLE I

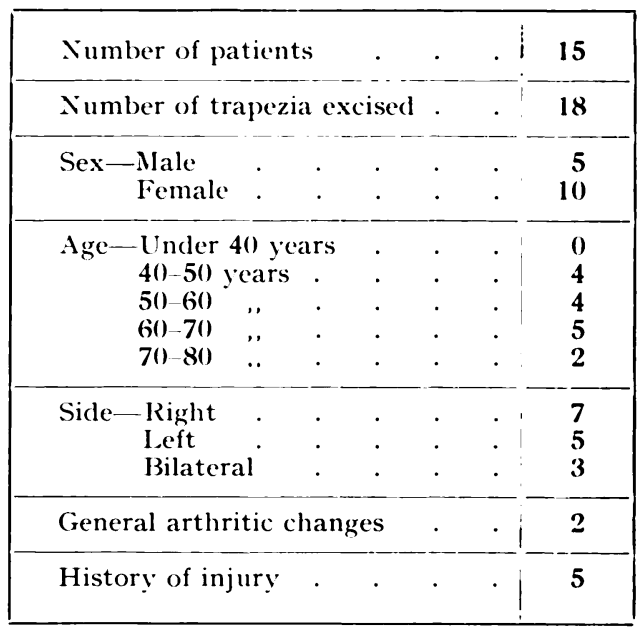
of pain about the base of the thumb, especially on movement. There was usually some obvious swelling and in four cases a diagnosis of ganglion had been made. Movement of the joint caused pain and crepitus could often be felt.

Radiographic appearances-Loss of joint space was associated with one or more of the following changes: simple osteophyte formation (Fig. 1); radial subluxation of the metacarpal bone (Fig. 2); or small ossicles about the joint (Fig. 3).

\section{TECHNIQUE OF OPERATION}

With a tourniquet applied, an incision is made parallel to extensor brevis pollicis in the distal part of the anatomical snuff box. The joint between the trapezium and first metacarpal is easily identified and opened widely; it may be found distended with fluid. Damage to the last part of the radial artery where it crosses the trapezium on its way to the deep palmar arch must be avoided. The ligaments are dissected off the bone in a proximal direction till the articulation with the scaphoid is reached. A raspatory is then inserted into this joint to retract and protect the artery while the articulations with the trapezoid and second metacarpal bones are defined. In working round the palmar surface and dissecting off the transverse carpal ligament it is important to keep close to the bone, or the tendon of flexor carpi radialis may be damaged in its groove in the trapezium. With careful dissection, using a small bladed knife the tendon should not be seen during the operation. Even when all the attachments of the bone have apparently been separated, it may be disinclined to

* Paper read at the Annual Meeting of the British Orthopaedic Association, 1948.

Vol. $31 \mathrm{~B}$, No. 4, NOVEMBer 1949 
come out. The temptation to lever the bone out forcibly must be resisted lest some fragments be left behind. Examination of the trapezium after removal shows loss of the articular cartilage with eburnation of the bone; in some cases the articular surface is grooved from long-standing subluxation.

Post-operative treatment - A firm pressure bandage is applied before removal of the tourniquet, but care is taken to avoid restriction of movements of the thumb. Active movements are started at once. Because of pain, many of these patients have long avoided movement of the first carpo-metacarpal joint and supervision is necessary to see that the thumb is moved through a full range.

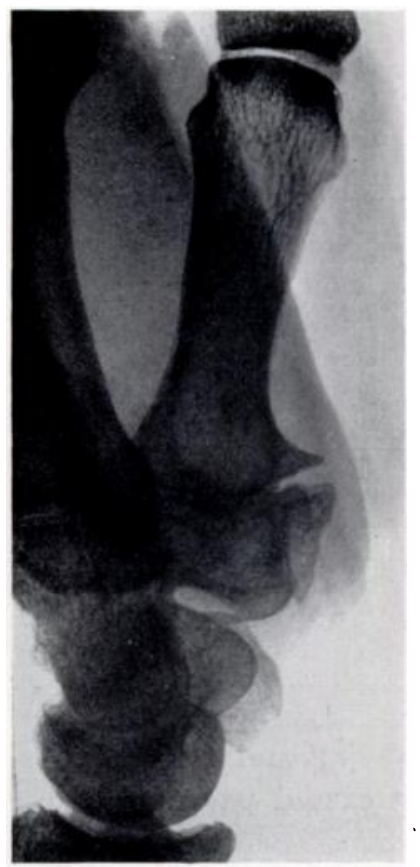

Fig. 1

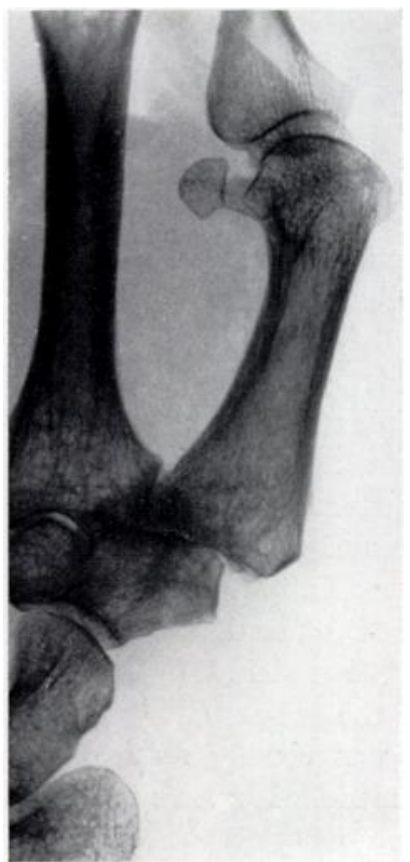

FIG. 2

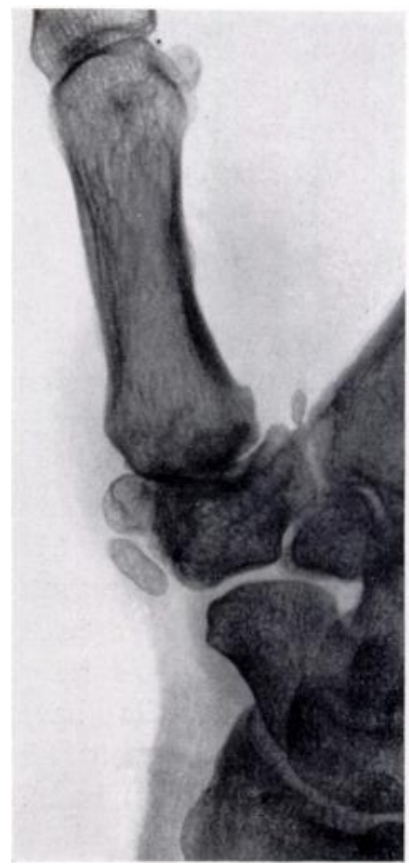

FIG. 3

Characteristic radiographic appearances of osteoarthritis of the trapezio-metacarpal joint. Loss of joint space is associated with osteophyte formation (Fig. 1), subluxation (Fig. 2), or formation of discrete ossicles (Fig. 3).

\section{RESULTS}

There are two patients in the series in whom the results are inferior and both show general arthritic changes. The first is the only patient who is not glad to have had the operation. She was aged seventy-one years and had generalised osteoarthritic changes, especially of the knees, to some extent of the hands, and slightly in the right trapezio-metacarpal joint. The left trapezium was excised a year ago on account of considerable pain on that side. Now there is full and painless movement of the first metacarpal bone and in this respect function is greatly improved. But the arthritic changes in the fingers have increased with wasting of the intrinsic muscles, so that the function of the hand as a whole has deteriorated.

The second patient was aged fifty-four years and had pain from severe osteoarthritis in both trapezio-metacarpal joints with marked subluxation. There were mild arthritic changes in the wrists and fingers, more of the rheumatoid type. Both right and left trapezia were removed and, though movements of the first metacarpal bones are now free and painless, 
there are slight effusions into the wrist joints and the patient complains that the thumbs are still weak.

The results in the remaining cases have been uniformly good. Two patients were operated upon early in 1944. One was a seamstress aged forty-six years, with increasing pain in the right thumb and difficulty in her work over a period of four years. She returned to full work after three weeks and the joint remains free from pain. Radiographs show a fragment of bone that has formed a small trapezium, but this does not seem to impair the function of the arthroplasty. The other patient was aged fifty-eight years; the left thumb was affected and the radiographs showed small discrete ossicles (Fig. 3). She has written to say that some time elapsed before she recovered efficient use of the thumb, which is now quite satisfactory.

The next patient, seen in 1945, was a farm worker aged forty-eight years, who had suffered for some years from pain in his right thumb which he dated from an injury. He resumed farm work two months after operation, but returned in 1947 complaining of the left thumb, which showed severe osteoarthritis. The trapezium on this side was removed; he has been doing full farm work ever since and is free from pain. Figure 4 shows the condition of the right thumb four years after operation. Another patient seen in 1945 was a woman aged fifty-three years with bilateral changes. Both trapezia were excised. She is very satisfied, but states that there is some weakness in the thumbs for such a movement as turning a tap.

The next patient was seen in 1946, a man complaining of pain and diminished movement of his right thumb. At that time he was a night watchman, but now does full work in the kitchen of a restaurant. Another patient operated upon in that year was a cowman aged forty-nine years who was unable to work because of severe pain in his right thumb (Fig. 2). One month after operation

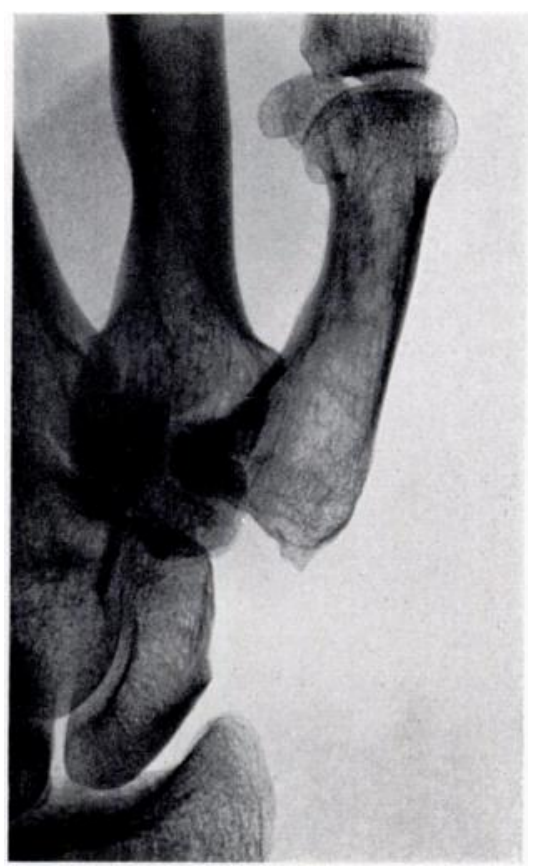

FIG. 4

The right wrist of a man aged forty-eight years taken four years after operation. The left trapezium was subsequently removed and he has returned to full farm work. he was milking twenty cows a day.

In more recent cases the results have continued to be satisfactory though older patients tend to be slow in gaining full recovery.

\section{SUMMARY}

1. The technique of excision of the trapezium for osteoarthritis of the trapezio-metacarpal joint is described.

2. The results of eighteen operations in fifteen patients are analysed.

3. The operation is of value particularly when the arthritis is monarticular. Results have been less satisfactory when the affection of the joint is part of a generalised arthritis.

\section{REFERENCES}

Forestier, J. (1922): Presse Médicale, 30, 695.

(ienvis, W. H. (1947): Proceedings of the Royal Society of Nedicine (Seetion of (Orthopaedics), 40, 492. (ienvis, W. H. (1948): Postgraduate Medical Journal, 24, 262.

RAY, M. B. (1933): Proceedings of the Royal Society of Medicine (Section of Physical Medicine), $27,193$.

VOL. $31 \mathrm{~B}$, NO. 4, NOVEMBER 1949 